\title{
Inexpensive plotters and digitizers for psychological research and instruction
}

\author{
H. J. DURRETT \\ Southwest Texas State University, San Marcos, Texas 78666
}

\begin{abstract}
The availability of low-cost microcomputers has been accompanied by the development of many inexpensive peripheral devices. The recent introduction of digitizers and plotters for use with microcomputers makes new research designs and instructional applications possible. This paper reports the characteristics and applications of one plotter and three digitizers of reasonably low cost. The application of digitizers in obtaining individual responses, quantifying data, preparing stimuli, and translating stimuli into machine-readable form is discussed. The application of plotters to hands-on instruction in data analysis and stimulus preparation is presented.
\end{abstract}

The availability of inexpensive microcomputers has been accompanied by the introduction of many inexpensive peripheral devices to be used with the microcomputers. Major manufacturers have generally produced less sophisticated models within existing product lines. This has had the effect of making some devices not previously considered for use in psychology more costeffective. Two such peripherals are digitizers and plotters. This paper discusses the general characteristics, capabilities, and application of digitizers and plotters from the perspective of the psychologist. Major emphasis is on proposed applications in psychological research and instruction.

Plotters and digitizers are members of the very large set of input-output (I/O) devices that are currently available for use with computers. Plotters and digitizers are generally recognized as members of the subset known as graphical $\mathrm{I} / \mathrm{O}$ devices. This subset includes all hardware that is generally used for "computer graphics." The term computer graphics is used to denote a collection of "techniques and applications wherein data is either presented or accepted by the computer in the form of line drawings or graphs" (Necas, 1976, p. 692). Computer graphic $\mathrm{I} / \mathrm{O}$ devices are generally classified into four main groups: (1) image input devices for transfer of hard-copy graphics into machine-readable form, (2) electromechanical plotters for the output of hard-copy graphics, (3) video display units for graphical capabilities, and (4) microfilm I/O devices.

Durrett (1979) discussed color video display devices for graphic display previously. At the present time no apparent need for local laboratory microform equipment exists. However, the need for the input and output of nonalphanumeric material has been apparent for some time. The increasing interest in imagery and pictorial representation by psychologists has made this capability desirable in the automated laboratory.

\section{DIGITIZERS}

Image input devices can be used in any application that requires the transformation of hard-copy images into proper form for computer processing. A digitizer is a member of a class of devices designated to help the user with the manual description of image data to be used for subsequent computer processing. The inexpensive digitizers now available are trace-analysis equipment that uses a cursor for tracing a graphic image. Digitizers consist of three basic components: a cursor, a digitizing tablet, and an $\mathrm{I} / \mathrm{O}$ interface.

The cursor serves as the manual means of translating the graphic image into $\mathrm{X}$ and $\mathrm{Y}$ coordinates that can be processed by a computer. Like a gunsight, the cursor has two thin lines that intersect at right angles at the center of a clear window. Generally, a small hole at the center of the cursor is available to insert a pen for a trace of the points transmitted to the computer. Using the pen also allows free-form input of hand-drawn figures in realtime. Figure 1 shows some of the many cursors available for various digitizing tasks.

The digitizing tablet is usually a translucent screen

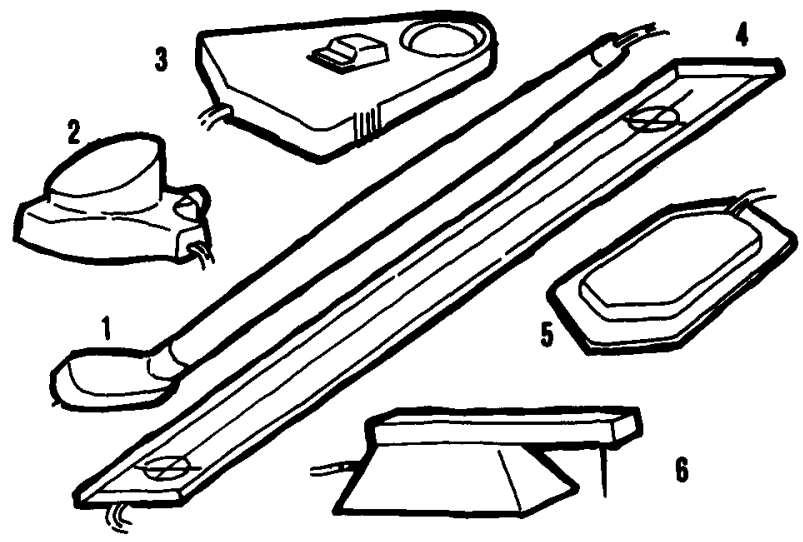

Figure 1. Examples of the various types of cursors that can be used with digitizing tablets. (1) Pencil unit. (2) Pencil unit (magnified). (3) Pencil unit fast: for high-speed work. Fast and easy to use. (4) Pencil unit (stable): for low-speed high-accuracy work. (5) Projected image: center readout. (6) Project image: double coordinate. 
that is used on a table top or light table. The graphic to be input is affixed to the tablet prior to digitization.

The $1 / O$ interface varies with the demands of the computer to which the digitizer is to be interfaced. Figure 2 shows a complete digitizer, consisting of digitizing tablet and cursor. This particular digitizer is a HI.PAD made by Houston Instruments for use with microcomputers. It usually has both an RS232C standard serial interface and a bit parallel interface, such as an IEEE-488 standard interface.

The operation of digitizing a graphic image consists of the following sequence of operations: (1) The graphic is positioned and affixed to a tray-like tablet, which may

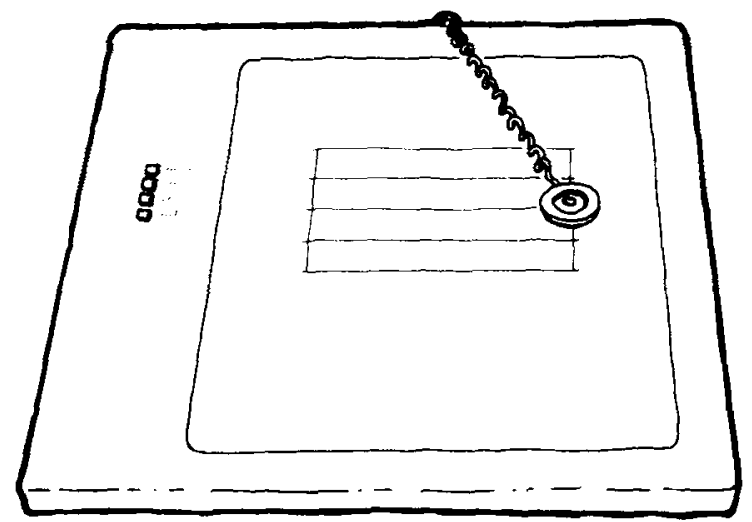

Figure 2. A typical inexpensive digitizer consisting of digitizing tablet and digitizing cursor: the Houston Instrument's HI-PAD. have a translucent screen. (2) The origin point located in the lower left corner of the screen is found and transmitted to the computer. (3) Points along the graphic are located within the crosshairs of a cursor. Either the cursor is sight positioned over existing data or a line is generated using an optional marker positioned in the cursor. (4) A button is pushed to transmit the $X$ and $Y$ coordinates of the located point. (5) Operations 3 and 4 are repeated as often as needed to manually transmit the graphic image to the computer.

Digitizers can be described by examination of their characteristics observed on several relevant dimensions. Of central importance are the dimensions of resolution and accuracy. Resolution refers to the number of $X, Y$ coordinate pairs that can be detected per unit of measurement. Accuracy is the amount of variance that can be expected to be associated with each digitization. Generally, as the resolution and the accuracy increase, the cost of the digitizer increases.

Also of importance are the various operating modes. The following modes are found on most digitizers: (1) Reset-In this mode the origin and all functions are reset to initial conditions. (2) Point-In this mode a single coordinate pair is transmitted on a signal from the cursor. (3) Stream-In this mode a continuous stream of coordinate pairs is transmitted as long as a signal is received from the cursor. (4) Remote-In this mode digitizing functions are controlled externally by the host computer. (5) Incremental-In this mode coordinate pairs are updated only when a change in value occurs.

Figure 3 presents a summary of digitizer features for

\begin{tabular}{|c|c|c|c|c|c|c|c|c|c|}
\hline Brand & $\underset{\text { Area }}{\text { Digitizing }}$ & $\begin{array}{l}\text { Overall } \\
\text { Size }\end{array}$ & Resolution & Accuracy & $\begin{array}{c}\text { Coordinate } \\
\text { Systemt }\end{array}$ & $\begin{array}{c}\text { Output } \\
\text { Data Rate }\end{array}$ & Interface & $\begin{array}{l}\text { Operating } \\
\text { Modes }\end{array}$ & Cost \\
\hline $\begin{array}{l}\text { Houston } \\
\text { Instruments } \\
\text { HI PAD(1) }\end{array}$ & $11^{\prime \prime} \times 11^{\prime \prime}$ & $\begin{array}{l}H=1^{\prime \prime} \\
W=17^{\prime \prime} \\
D=14^{\prime \prime}\end{array}$ & $\begin{array}{l}.005^{\prime \prime} \\
200 \\
\text { points/ } \\
\text { inch }\end{array}$ & $\begin{array}{l} \pm .015 \\
\text { in } \\
\text { relation } \\
\text { to } \\
\text { defined } \\
\text { origin } \\
.005 "\end{array}$ & $\begin{array}{l}\text { Absolute } \\
\text { cartesian } \\
\text { with } \\
\text { relocat- } \\
\text { able } \\
\text { origin }\end{array}$ & $\begin{array}{l}\text { Binary/ } \\
\text { BCD } \\
100 \\
\text { coordinate } \\
\text { pairs per } \\
\text { second }\end{array}$ & $\begin{array}{c}\text { RS-232C } \\
\text { Serial } \\
\text { and/or } \\
8 \text { bit } \\
\text { parallel }\end{array}$ & $\begin{array}{l}\text { Reset } \\
\text { Point } \\
\text { Stream } \\
\text { Remote }\end{array}$ & $\$ 795$ \\
\hline $\begin{array}{l}\text { Summa } \\
\text { Graphics } \\
\text { Bit Pad One } \\
\text { (2) }\end{array}$ & $11^{11} \times 11^{11}$ & $\begin{array}{l}H=1.60^{\prime \prime} \\
W=15.56^{\prime \prime} \\
D=15.56^{\prime \prime}\end{array}$ & $\begin{array}{l}.005 " \\
200 \\
\text { points/ } \\
\text { inch }\end{array}$ & $\pm .08 \%$ & $\begin{array}{l}\text { Absolute } \\
\text { cartesian } \\
\text { with } \\
\text { relocat- } \\
\text { able } \\
\text { origin }\end{array}$ & $\begin{array}{l}\text { Binary/ } \\
\text { BCD } \\
100 \\
\text { coordinate } \\
\text { pairs per } \\
\text { second }\end{array}$ & $\begin{array}{l}\text { RS-232C } \\
\text { Serial } \\
8 \text { bit } \\
\text { parallel } \\
\text { IEEE } 488\end{array}$ & $\begin{array}{c}\text { Reset } \\
\text { Point } \\
\text { Stream } \\
\text { Remote } \\
\text { Incremental }\end{array}$ & $\begin{array}{l}\$ 700 \\
\text { to } \\
\$ 1000 \\
\text { Depending } \\
\text { on } \\
\text { options } \\
\text { selected }\end{array}$ \\
\hline $\begin{array}{l}\text { Tàlos } \\
\text { The Simple } \\
\text { One }(3)\end{array}$ & $11^{\prime \prime} \times 11^{\prime \prime}$ & $\begin{array}{l}H=1^{\prime \prime} \\
W=17.75^{\prime \prime} \\
D=17.75^{\prime \prime}\end{array}$ & $\begin{array}{l}.005^{\prime \prime} \\
200 \\
\text { points/ } \\
\text { inch }\end{array}$ & $\pm .02^{\prime \prime}$ & $\begin{array}{l}\text { Absolute } \\
\text { cartesian } \\
\text { with } \\
\text { relocat- } \\
\text { able } \\
\text { origin }\end{array}$ & $\begin{array}{l}\text { Binary/ } \\
\text { BCD } \\
100 \\
\text { coordinate } \\
\text { pairs per } \\
\text { second }\end{array}$ & $\begin{array}{l}16 \text { bit } \\
\text { parallel } \\
\text { binary } \\
\text { Bisequen- } \\
\text { tial } \\
\text { format } \\
\text { TTL signal } \\
\text { level } \\
\text { RS-232C }\end{array}$ & $\begin{array}{l}\text { Point } \\
\text { Run } \\
\text { (Switch } \\
\text { se)ect- } \\
\text { abie) }\end{array}$ & $\$ 1400$ \\
\hline
\end{tabular}

Figure 3. Summary of characteristics of three low-cost digitizers. (1) HI PAD and HI PLOT-Houston Instruments, a division of Bausch \& Lomb, One Houston Square, Austin, Texas 78753, (512) 837-2820. (2) Bit Pad One-Summagraphics, 35 Brentwood Ave., Box 781, Fairfield, Connecticut 06430, (203) 384-1344. (3) Talos Systems, Inc., 7419 East Helm Drive, Scottsdale, Arizona 85260, (602) 948-6540. 
three typical digitizers. Many digitizers are available in increasing price ranges. These are not included, since this paper is not a survey of all digitizers currently being marketed. The digitizers summarized were selected for their low cost (i.e., less than $\$ 1,500$ ). Psychologists interested in using digitizers could begin with the experimental use of these devices before progressing to more elaborate digitizers.

\section{Applications of a Digitizer as a Graphic Input Device}

Obviously, digitizers can be used in the psychological laboratory to digitize graphical input such as bar charts, histograms, frequency polygons, and diagrams. This conversion from graphic form to machine-readable representation can be for the purpose of stimulus preparation and presentation or data analysis. However, there are other productive ways of using a digitizer in the psychological laboratory. A few of these applications are discussed below.

A digitizer as a customized input terminal. A digitizer tablet can be used as a customized input device for special experimental requirements or data collection. This is accomplished by placing a graphic on the tablet that divides the digitizing area into labeled blocks. The blocks can represent various responses to be made by individuals or various conditions to be observed and reported as data. As each condition occurs, the cursor is placed anywhere within the boundaries of a block, and the coordinate pair is transmitted. The host computer can then perform range-checking operations on the coordinates to determine which block was indicated. If blocks are uniform through the coordinate digitizing space module, arithmetic can be performed on the coordinates to identify the precise block in which the cursor is located. In conditions requiring real-time observation of behavior, the cursor can be allowed to operate in continuous stream mode and freely move among the blocks as the behavior associated with each block occurs. The total number of coordinates transmitted from a given block provides a reasonably accurate measure [i.e., \pm 1 unit/(coordinates/second)] of the duration of each behavior.

The interchanging of response templates thus allows a very flexible, inexpensive, and general-purpose input device to be created. It can obviously perform any task available on a keyboard or specialized button-switch interface. It can be especially useful with children.

A digitizer as a data quantifier. Many psychologists employ testing and measuring instruments that require indicated responses on scaling lines. The quantification of this data is often tedious and error prone. A digitizer can be used to quickly quantify scaling data directly from the measuring instrument. Also, data collected from physiological recorders must be quantified by visual and manual techniques. A digitizer can perform these tasks in a quick and accurate manner.

Testing data from multiple-choice inventories can be quickly entered and scored using a digitizer. The correct sequence of answers is first entered and stored. Then each response sheet is entered by placing the cursor over the indicated response. This technique is especially desirable when only a limited number of response forms are to be processed or the form is in the pilot stage. Data entered in this way produce fewer errors than those transcribed and entered by manual, tab card, or terminal techniques.

A digitizer as a free-form graphic input device. When drawing with pen and paper, the resolution is as fine as the point of the pen. This makes straight lines drawn freehand somewhat less than straight due to inherent flaws in the output device. However, even a psychologist can draw straight-line diagrams with a digitizer. By using a course grid pattern, the "artist" draws with the blocks, and the digitized output is processed by the host computer into fixed straight lines. In this way, rapid translation of graphic ideas into graphics of acceptable quality can be accomplished.

\section{ELECTROMECHANICAL PLOTTERS}

Image output devices can be used in any application that requires the transformation of computer information into a hard-copy format. The resulting hard copy is usually more meaningful and easier to use than extensive alphabetic or numeric listings. Plotters have, due to their cost, been justified only when the volume of graphic presentations of output data made the preparation of manual graphics uneconomical. However, recent lowcost electromechanical plotter devices make low-volume and specialized use cost effective.

Electromechanical plotters are impact-plotting devices that operate on a basic incremental principle. Plotters generally operate in a drift-free digital fashion. This allows any size, type, and orientation of letters, symbols, lines, and axes. All inexpensive electromechanical plotters use an eight-vector structure for representing movement in the $\mathrm{X}, \mathrm{Y}$ coordinate plane, as shown in Figure 4.

Electromechanical plotters use either flatbed or drum, but currently only low-cost flatbed plotters are

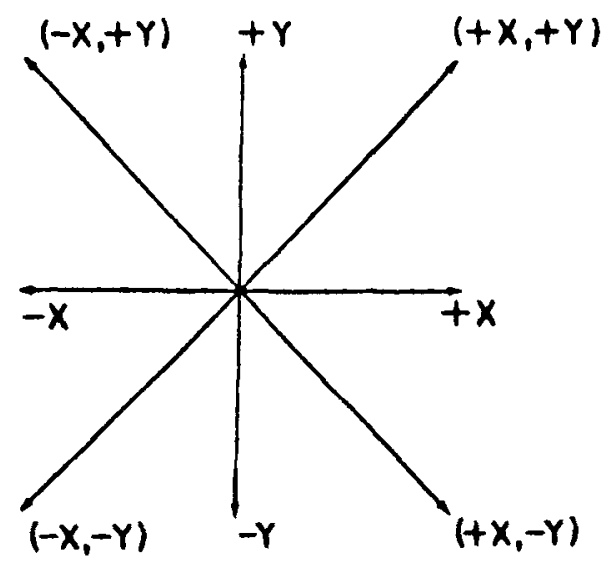

Figure 4. Eight-vector structure for representing movement in the Cartesian coordinate plane. 
available. On a flatbed plotter, a plot is produced by lateral motion of the beam and vertical motion of the pen carriage. The pen cartridge holds either ball-point or liquid ink pens of any color for producing the plot. During the process of plotting, the display is continuously visible. No special paper is required, but most plotters have a variety of prepared forms suitable for outputting plots.

When plotting commands are transmitted to the plotter to move one of the eight directions shown in Figure 4 or to move the pen up or down, sufficient time must be allowed for pen-up and pen-down operations on less sophisticated plotters. Successive commands are issued by the host computer to the plotter to cause increments of the pen in one of the eight possible directions. User software is required to interface the plotter to the host computer. To make its use convenient, a translation from coordinate pairs and pen increments must be performed. Simple routines are provided for computing the best incremental straight line between two points. Other user software can be written to draw legends, coordinate axes, and other alphanumeric symbols.

Currently, only one low-cost electromechanical plotter is being marketed to my knowledge, the Houston Instrument HI PLOT (Figure 5). Figure 6 presents a summary of the HI PLOT's characteristics. Figure 7 presents an example of plotter output.

\section{Plotters as Graphic Output Devices}

The availability of a quick, accurate, and convenient means of graphically representing numerical data would assist most psychologists. But the usefulness is readily apparent when the plotter is connected directly to an on-line computer. Daily summaries of data trends could guide experimental studies. Perhaps of greater significance is classroom use. Use in the statistics and experimental lab has provided students with rapid graphic representation of their data sets. Actually seeing data being input and plotted appears to generate student interest. The plotter also serves as a means of outputting hard copy from information generated by computer simulations or input from a digitizer.

Plotters can also be used as chart recorders for events

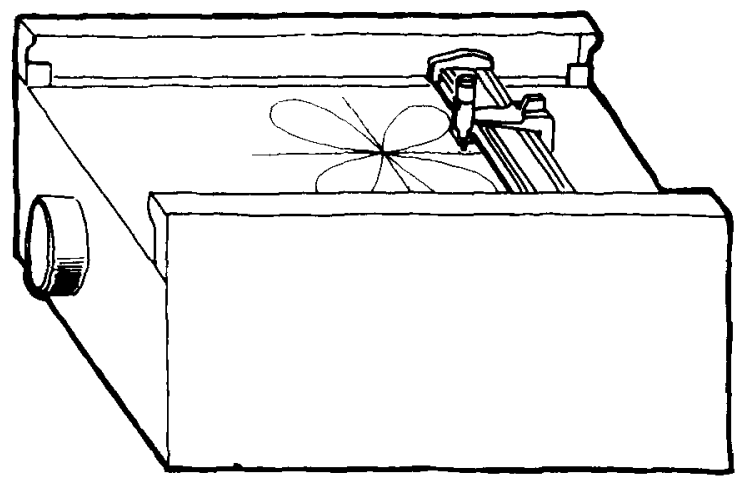

Figure 5. A drawing of the Houston Instruments' HI-PLOT Plotter.

$\begin{array}{ll}\text { Plotting Area: } & 7 \times 10 \text { in. } \\ \text { Total Surface Area: } & 8.5 \times 11 \mathrm{in.} \\ \text { Overall Size: } & \mathrm{H}=6 \mathrm{in} ., \mathrm{W}=15 \mathrm{in} ., \mathrm{D}=10.5 \mathrm{in} . \\ \text { Resolution: } & 200 \text { or } 100 \text { increments/in. } \\ \text { Accuracy: } & .005 \text { in./increment or } .01 \text { in./increment. } \\ \text { Mechanism: } & \begin{array}{l}\text { Reversible stepper motor complete with } \\ \text { drive electronics to give bidirectional }\end{array} \\ & \text { movement. } \\ \text { Interface: } & \text { RS-232C serial asynchronous or parallel } \\ & \text { six-line TTL. } \\ \text { Controls: } & \text { Power switch, X-axis manual locator, } \\ & \text { Y-axis manual locator, chart hold/load } \\ & \text { slide, input connector. } \\ \text { Cost: } & \$ 1,085 .\end{array}$

Figure 6. Summary of characteristics of HI-PLOT plotter.

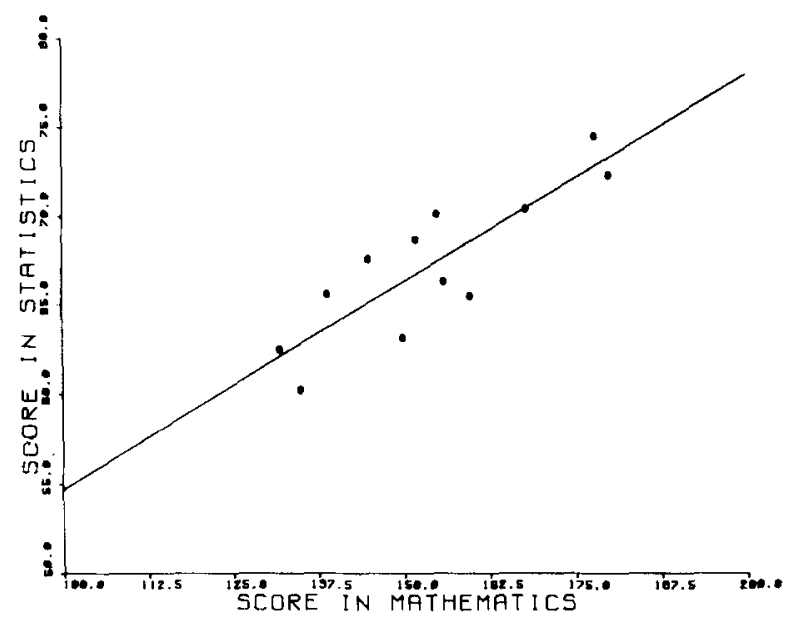

Figure 7. An example of plotter output.

of long duration or as frequency counters for events of short duration. Stimulus preparation for experiments is also made more convenient. Slides can be made from the plotter output for experiments and paper presentation. By changing pen color, highlights can be added.

\section{SUMMARY}

Computer graphic devices have found wide use in other scientific fields. Their cost has now approached a level making them cost effective for use in the psychology classroom and student laboratory. Using an inexpensive digitizer, many types of free-form input to computers are possible. Output of this information can be quickly accomplished with low-cost plotters. New applications will undoubtedly emerge as more laboratories acquire these computer graphic devices.

\section{REFERENCES}

Durrett, H. J. Color display systems: The state of the art. Behavior Research Methods \& Instrumentation, 1979, 11, 127. 130.

Necas, J. Input-output devices. In A. Ralston \& C. Meek (Eds.), Encyclopedia of computer science. New York: Petrocelli/ Charter, 1976. 